\title{
A FRAGILIDADE DA NOÇÃO DE DIREITOS HUMANOS NO MARCO DA CRISE DOS FUNDAMENTOS DA RAZÃO MODERNA
}

\section{Edna Raquel Hogemann ${ }^{1}$}

\section{Resumo}

A questão abordada nesse ensaio diz respeito a uma reflexão crítica quanto às razões para uma ausência de efetividade dos direitos humanos, discutindo-a a partir do pensamento denominado por Santos como contrahegemônico. $\mathrm{O}$ interesse pela reflexão a respeito da insuficiência fundamentadora da lógica dos direitos humanos em seu caráter eurocêntrico surge, na medida em que, apesar de os fundamentos teóricos dos direitos humanos já se terem constituídos em tema largamente pesquisado, o que não significa que não mereça outros olhares, por seu turno as questões relativas à ineficácia quando da aplicação normativa dos direitos humanos estão a suscitar um maior aprofundamento. A proposta é, a partir de uma retrospectiva do contexto jusfilosófico e político em que nasceu a noção de "direitos humanos", apontar seus fundamentos, e as questões inerentes a sua efetivação histórica, tendo em conta a contribuição do Jusnaturalismo e do Positivismo Jurídico, da modernidade racional, lógica e positivista, num universo dominado pelo Estado de Direito. Propõe-se também, situar a fala dos direitos humanos no atual contexto sócio-político de crise dos fundamentos da razão, paradigma fundante e estruturador da sociedade, carentes de uma mudança. Toma-se como referencial teórico o pensamento de autores como Michel Villey, Costas Douzinas, Gilles Lipovetsky, Peter Sloterdijk, Makau, Mutua e Boaventura de Souza Santos, dentre outros. Nesta direção e, diante da meta aqui estipulada e apresentada no transcorrer do texto, acredita-se que as diretrizes oriundas do método dialético parecem oportunas para a orientação do desenvolvimento da pesquisa apresentada. Privilegiar o método dialético implica em reconhecer que o estudo se propõe a fazer uma leitura crítica da noção de direitos humanos. Tem-se por objetivo assinalar elementos que demonstrem os direitos humanos como uma produção jurídica e política de feição eurocêntrica, dentro de um viés estritamente racionalista e dogmático, próprios da modernidade, com vistas a evidenciar a hipótese segundo a qual a fragilidade da noção de direitos humanos e sua insuficiência fundamentadora, estão associadas à fraqueza de sua natureza normativa e a um racionalismo exacerbado em que, contraditoriamente, o legal ultrapassa o humano, a ética e a solidariedade.

Palavras-chave: Direitos humanos; eurocentrismo; modernidade; insuficiência fundamentadora

\section{INTRODUÇÃO}

A questão que será abordada nesse ensaio diz respeito a uma reflexão crítica quanto às razoes para uma ausência de efetividade dos direitos humanos, discutindo-a a partir do pensamento denominado por Santos (2013, p. 13) como contra hegemônico. O interesse pela reflexão a respeito da inefetividade dos direitos humanos

\footnotetext{
${ }^{1}$ Pós-doutoranda em Direito, professora da Universidade Estácio de Sá/RJ e da Universidade Federal do Estado do Rio de JaneiroUNIRIO.E-mail: ershogemann@gmail.com
} vol.09, no. 04, Rio de Janeiro, 2016.pp. 1787-1805 
surge, na medida em que, apesar de os fundamentos teóricos dos direitos humanos já se terem constituídos em tema largamente pesquisado, o que não significa que não mereça outros olhares, por seu turno as questões relativas à ineficácia quando da aplicação normativa dos direitos humanos estão a suscitar um maior aprofundamento. É de se observar que muitos dos trabalhos que se voltam para a análise da produção do corpus dos direitos humanos no que diz respeito à sua validade, eficácia e fundamentos, partem do pressuposto segundo o qual a gênese dos direitos humanos é marcada por sua intensa complexidade que inter-relaciona diversas dimensões desde direitos individuais a direitos coletivos e difusos, vinculada a um discurso em que a visão ocidental é predominante, na medida em que são considerados como produto dos movimentos políticos e filosóficos determinados pelo contexto europeu moderno. Assim, ao se tratar da trajetória dos direitos humanos, deve-se ter em vista a conjunção das lutas políticas e religiosas inglesas, francesas, norte-americanas dos séculos XVII e XVIII, com a tradição teórica racionalista da modernidade.

O presente ensaio propõe-se precisamente a problematizar as concepções jus-histórico-filosóficas que fornecem lastro ao discurso predominante dos direitos humanos. A partir da categoria de "assujeitamento" de Giacioa, da metáfora tridimensional (salvador-vítima-selvagem) e da teoria ética desenvolvidas respectivamente, por Mutua e MacIntyre, discute-se as contradições da compreensão histórico-geográfica dos direitos humanos, e, em paralelo se busca evidenciar as razões pelas quais o discurso, que posiciona as suas origens na Modernidade Ocidental, consagrou-se como um discurso hegemônico. Por outro lado, utilizando-se as contribuições de Villey, Sloterdik e Lipovetsky perquire-se o projeto da modernidade, berço dos direitos humanos, revelando-se suas limitações, desigualdades e ambiguidades, chegando ao seu esgotamento. Problematizando-se o conceito de racionalidade cunhado pelo Iluminismo, busca-se evidenciar que, sob o pano de fundo de uma pretensa neutralidade, oculta-se um projeto de exclusão e opressão humana, reforçado pela ideia de raça e pelo exercício de um poder anti-humanista, nos termos de Said, juridicamente indefensável.

\section{DIREITOS HUMANOS COMO PRODUTO DA MODERNIDADE}

Os direitos humanos são inegavelmente o resultado de um longo processo histórico de lutas e de resistência à opressão, que deita suas raízes no Cristianismo, no Medievo, com a afirmação da defesa da igualdade entre os homens numa mesma dignidade, fruto da condição de igualdade e semelhança ao próprio Criador, responsável último pela criação de um ordenamento normativo cuja aspiração maior era o ideal de justiça.

Desde a desobediência de Antígona, filha de Édipo, contra a ordem injusta do rei Creonte até as grandes revoluções dos séculos XVIII, XIX e XX, desde as revoltas dos escravos até o movimento de descolonização, o movimento pelos direitos civis e o movimento feminista, o anseio "natural" permanente do ser humano tem sido resistir à dominação e opressão. Os direitos naturais no século XVIII e os direitos humanos após a 2a Guerra Mundial e nas lutas do mundo em desenvolvimento expressaram esse anseio. Neste sentido, a finalidade (o fim) dos direitos humanos é a resistência. (DOUZINAS, 2015, p. 01). 
As Luzes da Idade Moderna colocaram no centro dos holofotes filosóficos a razão humana. Os racionalistas dos séculos XVII e XVIII, à luz da razão, deram um novo formato à teoria do direito natural, rompendo com a ordem de feição divina.

Para os racionalistas a liberdade faz parte da condição humana e, desse modo, os homens nascem livres por natureza e dotados de certos direitos inatos dos quais não se apartam quando entram em sociedade. Sob tal prisma de compreensão a atual concepção dos direitos humanos corresponde a um projeto da modernidade.

Todo o período pré-moderno estava fundado na noção de communitas, como uma ordem natural posta, uma comunidade universal, pré-determinada e inabalável de caráter ontológico-metafísico, o domínio do "Ser".

A modernidade inaugura uma nova compreensão, produto de uma longa elaboração, já no final da Idade Média, e assentado em bases culturais, filosóficas, sociais e históricas desde a Antiguidade. Essa nova compreensão situa a comunidade como sociedade construída a partir de um fundamento contratual, como resultado da experiência e do empenho cultural de homens detentores de uma racionalidade que exercem num acordo voluntário.

A causa e consequência dessa transformação residem na emergência do indivíduo, posição de pessoa dotada de subjetividade ultrapassando as concepções da antiga Grécia e da cristandade da Idade Média, centradas, respectivamente, na polis e na "igreja universal". A figura da pessoa como valor essencial de todo um complexo ético-jurídico tornou-se sólida tão-somente com a união das filosofias antigas, em particular a tradição estóica, com uma ainda incipiente teologia cristã.

No período renascentista, a definição de pessoa recebeu novo elemento, o da dignidade humana, exaltada e estudada pelos pensadores daquela época, configurando-se verdadeiro alicerce da luta pelos direitos, sobretudo de ordem política, impulsionada nos séculos seguintes.

Os iluministas vão elaborar suas ideias sobre sociedade, estado e direito, com base no universo europeu, tido como modelo universal. O discurso jurídico, por exemplo, foi construído tendo em conta a concepção relativa ao progresso e evolução. $\mathrm{O}$ estado de natureza consubstanciou-se como o arquétipo jurídico e político próprio dos povos colonizados (bárbaros), enquanto o estado civil era privilégio da sociedade a que o "sujeito de conhecimento" pertencia, ou seja, o europeu (salvador) colonizador, pensador iluminista, que invade, saqueia e "coloniza" num processo de subalternização dos saberes locais "bárbaros".

Em paralelo, o Iluminismo exalta o respeito e o culto ao homem como senhor de seu próprio destino, tendo como referencial uma cosmovisão totalmente racional, com ênfase no princípio da liberdade e da autonomia individual.

Desde o Bill of Rights inglês, sobrevindo a Declaração Americana da Independência de 1776, até a Declaração dos Direitos do Homem e do Cidadão, em 1789, consagradoras das liberdades públicas, aditou-se a expressão legal da perspectiva iluminista baseada na promessa de emancipação do indivíduo das formas de vol.09, no. 04, Rio de Janeiro, 2016. pp. 1787-1805 
opressão política. O âmbito dos direitos humanos, desde então, foi-se largueando e revelando os direitos econômicos e sociais.

Os direitos do homem nasceram no discurso político moderno como um pressuposto necessário para a autonomia dos particulares em face do Estado demarcado por governos absolutistas numa Europa em fase de expansão capitalista. A ideologia liberal moderna incorporada nas Declarações tem como ponto de partida os direitos naturais do homem tal como estabelecidos na teoria do contrato social, justificados pela natureza racional do homem, a serviço de um projeto liberal e burguês.

Essa racionalidade o faz senhor e titular de si mesmo (jus in se ipsum), como também de suas escolhas, motivo pelo qual seria uma violência impedir o homem de livremente fazer uso de sua razão e, na medida em que os direitos naturais procedem da hipótese (real ou imaginária) de um estado pré-social ou de natureza, a sua concepção antropológica fundante é a do indivíduo que existe e subsiste sozinho e onde a sociedade não é o momento de realização do humano, tornando a alteridade uma noção meramente formal, quando não inconveniente.

No entanto, se por um lado o enaltecimento da ideia de poder do ser humano enquanto sujeito configura-se como a base da igualdade de direitos entre os cidadãos, mesmo não pertencentes à nobreza ou ao clero, por outro, e paradoxalmente este promove o aniquilamento da subjetividade, na medida em que foi estabelecido um pretenso saber jurídico universal partindo da concepção segundo a qual seria possível a existência de sujeitos de conhecimento neutros e apartados do tempo e do espaço.

Esse processo desaguou nas ondas de um racionalismo exacerbado e de uma excessiva perspectiva cartesiana de mundo, na qual a realidade se fragmenta para ser objeto de análises que não necessariamente refletem o todo ${ }^{2}$.

Mas cumpre alertar para a contradição basilar que se revela em todo esse processo: se é verdade que no plano jurídico político, sob a égide da modernidade ilustrada europeia, a antiga figura do súdito se converte em sujeito de direitos, sobretudo após a declaração dos direitos humanos e suas garantias, nascendo aí a cidadania em seu sentido moderno, paralelamente esse mesmo sujeito de direitos nasce de modo antinômico. Ele é submetido ao que Giacoia Junior (2014, p. 03) denomina "assujeitamento", na medida em que aquele poder, que outrora se expressava em deixar viver e fazer morrer, agora se transmuta em soberania que deixa morrer e faz viver. "Há uma inversão de perspectivas".

\footnotetext{
2 "Qual o resultado? O homem moderno alienou-se de si mesmo, de seus semelhantes e da natureza. Ele foi transformado numa mercadoria, experimenta suas forças vitais como um investimento que precisa the proporcionar o maior lucro capaz de ser obtido nas condições de mercado existentes. As relações humanas são essencialmente as relações entre robôs alienados, cada um dos quais baseia sua segurança em ficar junto do rebanho e não ser diferente dele em pensamento, sentimentos e atos..." (FROMM. 2006, p.106).
} 
Direito e Moral e os valores transcendentes passam a situar-se em círculos independentes, ou seja, as normas eram produzidas sem levar em consideração os valores históricos, sociais, econômicos e políticos da sociedade; a ideia é de que o único direito válido é o direito posto pelo Estado.

Contudo, o que se vê é uma limitação dos parâmetros científicos, e inclusive jurídicos que foram utilizados para desenvolver o social na época moderna. E precisamente por conta dessa descrença nos modelos passados se abre a possibilidade de se refletir em um novo modelo de referência, de fundamentação. Como destaca Barroso (2001, p. 15):

O Direito, ao contrário de outros domínios, não tem nem pode ter uma postura puramente descritiva da realidade, voltada para relatar o que existe. Cabe-lhe prescrever um dever-ser e fazê-lo valer nas situações concretas. O Direito tem a pretensão de atuar sobre a realidade, conformando-a e transformando-a. Ele não é um dado, mas uma criação. A relação entre o sujeito do conhecimento e seu objeto de estudo - isto é, entre o intérprete, a norma e a realidade - é tensa e intensa. $\mathrm{O}$ ideal positivista de objetividade e neutralidade é insuscetível de realizar-se. Ele não é um dado, mas uma criação.

É com essa leitura ampla do projeto da modernidade, fulgurado pelas luzes do Iluminismo ${ }^{3}$, que se percebe uma correspondência excessiva a determinadas expectativas e a exclusão confessadamente de outras.

Para MacIntyre (1984, p.223), os filósofos do projeto iluminista buscaram tanto uma justificativa racional para as ações humanas, que esqueceram de elaborar uma moralidade que considerasse as condições sócio históricas da vida dos sujeitos, ou seja, não conseguiram dar conta dos problemas que emergiam com a modernidade. Essa consagração máxima da racionalidade leva a uma cultura na qual 'uma pessoa pode ser inteiramente racional sem ser justa'.

A tese de MacIntyre (1984, p.228) em relação ao pensamento liberal, próprio desse momento histórico, vai no sentido de que muito embora tenha havido todo um esforço em apartar da seara pública a noção de bem de cada um, no liberalismo moderno o bem maior se configura na reprodução e manutenção de uma ordem social e política que se revela tão excludente como qualquer tradição aprisionada em seus próprios padrões de racionalidade. O resultado é um cinismo que se generaliza no que diz respeito à legitimidade da discussão racional, na medida em que argumentos não mais são reconhecidos enquanto expressão de racionalidade e se instrumentalizam como armas, em técnicas retoricas cujo objetivo é o da submissão dos opositores.

O projeto iluminista fracassa na medida em que, ao mesmo tempo em que libera o agente moral das amarras relativas às hierarquias e teleologias, o que o possibilitou a tornar-se um sujeito autônomo e soberano no estabelecimento dos conteúdos morais; por outro lado, promoveu tal transformação nas regras morais a ponto que perdessem seu estatuto factual e categórico tornando-se meros instrumentos dos desejos e vontades arbitrários de um agente moral individual. Assim, o iluminismo tornou urgente e necessário o resgate do agente

\footnotetext{
${ }^{3} \mathrm{O}$ projeto iluminista representa uma pretensão de racionalidade que exige a adesão de todos os seres racionais a certos princípios independentes de qualquer tradição ou particularismo, que é a característica marcante da modernidade como descreve MacIntyre em seu livro Justiça de Quem? Qual racionalidade? (1991) (ALBERTUNI, Carlos Alberto, 1997, p. 294).
} 
moral individual do esvaziamento e da perda da validade racional à linguagem moral.

Esse posicionamento crítico é construído no que diz respeito à concepção kantiana do imperativo categórico. Kant defende que o homem deve agir guiado por máximas próprias, autônomas, como se fossem leis universais. Para MacIntyre (1984, p.322), no entanto, na vida real, isto não é factível. O homem como agente moral é um ser localizado, condicionado conjunturalmente e com laços que o vinculam a uma comunidade com uma dada tradição. Pretender que é possível criar abstratamente um homem universal, capaz de se libertar das circunstâncias e apartado da comunidade e da tradição, é o mesmo que ignorar a evidência da evolução histórica e da diversidade cultural. Esse posicionamento conduz o autor à afirmação da atual ausência de critérios morais que possam imprimir uma direção moral nas modernas sociedades ocidentais.

Em razão de suas limitações, desigualdades e ambiguidades, o projeto da modernidade chega ao seu esgotamento, o que leva à situação presente, definida por Santos (1995, p.p. 103-107) como "situação de transição", conhecida como pós-modernidade e por este mais constantemente referida como transição paradigmática.

Como leciona Santos (2006, p.107):

Afirmar que o projeto da modernidade se esgotou significa, antes de mais nada, que se cumpriu em excessos e déficits irreparáveis. São eles que constituem a nossa contemporaneidade e é deles que temos de partir para imaginar o futuro e criar as necessidades radicais cuja satisfação o tornarão diferente e melhor que o presente.

Diante desse quadro nada promissor, que irá impactar o discurso dos direitos humanos, urge buscar-se novas formas de tradução que possam se configurar possibilitadores da superação da ineficácia e da incompletude. Isso significa, mais que tudo, refletir criticamente sobre nossa contemporaneidade, as perspectivas que se descortinam e como o Direito, enquanto reflexo e motor da sociedade, pode desempenhar um papel de fundamental importância na ruptura com os modos de vida dominados pela racionalidade asséptica, pelo individualismo egoísta, pela lógica reificada do mercado, bem como na afirmação de uma ética em que o Outro não figure como mero opositor ou concorrente. Cumpre ao Direito o arranjo entre legalidade e eticidade para que os ideais democráticos e a vida em todas as suas múltiplas manifestações, se realizem na garantia da justa afirmação de um Humanismo includente e possibilitador da realização coletiva.

\section{A METÁFORA DO DISCURSO DOS DIREITOS HUMANOS}

Metáfora é uma figura de linguagem onde se usa uma palavra ou uma expressão em um sentido que não é muito comum, revelando uma relação de semelhança entre dois termos. Aristóteles, na Poética, define metáfora como "a transposição do nome de uma coisa para outra, transposição do gênero para a espécie, ou da espécie para o gênero, ou de uma espécie para outra, por via de analogia” (Aristóteles, 1959, p. 312). Utilizar uma metáfora, então, sugere empregar um termo em lugar de outro, seja como desvio, como um empréstimo semântico ou vol.09, no. 04, Rio de Janeiro, 2016. pp. 1787-1805 
como uma substituição, a partir de uma descoberta.

A descoberta da linguagem dos direitos humanos pelo próprio povo, considera Sloterdijk (2011, p. 110), foi um passo fundamental. Para esse autor, muito embora esses direitos que são articulados desde aquela que foi considerada a maior e mais generalizada revolta popular da Europa, a Guerra dos Camponeses alemães, datada de 1525 chegando até a resistência russa e polaca de nosso tempo, sejam concebidos como direitos cristãos, o componente acrescido pelas Revolução Americana e Revolução Francesa, lhes permite serem entendidos como direitos naturais seculares. E prossegue:

Mistura de revolta e de reivindicações de liberdade, o sentimento exaltante de ser não um escravo (robot), mas também um ser humano, deu a primeiro movimento operário a sua força moral, psicológica e política, a qual aumentou ainda com a repressão. [...] enquanto a miséria do proletariado era tão enorme como o provam os documentos do século XIX, bastava a descoberta do sentimento dos direitos humanos para propiciar necessariamente ao operário um núcleo político de um eu (SLOTERDIJK, 2011, p. 110).

No entanto, é de admitir-se que sobre a construção histórica dos direitos humanos o evento mais importante situa-se no século XX; compreende o período 1945-1948, quando os aliados abrem os portões dos campos de concentração nazistas e tomam consciência dos crimes e dos horrores praticados contra milhões de seres humanos (judeus, comunistas, ciganos e homossexuais) durante a 2a Guerra Mundial, sob a égide e o rigor do Estado de Direito alemão. A experiência nazifascista não poderia se repetir.

A Declaração Universal dos Direitos Humanos, assinada em 1948, anunciou o que seria início de uma nova era em que a assunção da promoção dos direitos humanos constituiria interesse da comunidade internacional. Tal declaração, embora de vital importância, na medida em que seu texto foi referenciado em algumas constituições, não é dotada de coercibilidade jurídica para que todos os Estados a observem, o que levou à necessidade da elaboração de inúmeros protocolos que reforçassem e dessem especialidade aos direitos presentes na declaração, visando a seu reconhecimento e aplicação pelos Estados.

Tem-se, então, que, desde 1948, as Nações Unidas adotaram a Declaração universal dos Direitos Humanos, e com ela uma profusão de normas, processos e instituições para definir e proteger os direitos humanos. Hoje praticamente todas as causas procuram traduzir-se sob a linguagem de direitos. Mas, mesmo assim, essa vinculação universal ao idioma dos direitos não conseguiu criar um terreno comum e um possível acordo quanto ao âmbito, conteúdo e base filosófica dos direitos humanos.

Por outro lado, cumpre apontar que o mesmo século XX que consagra os direitos humanos, foi marcado por duas guerras mundiais e pelo horror absoluto do genocídio ${ }^{4}$ constituído como projeto político e econômico, com a acumulação de refugiados, vítimas da perseguição das minorias étnicas, e permaneceu assombrado frente ao surgimento da desnacionalização em massa provocado pelos movimentos totalitários. Aquele século teve seu

\footnotetext{
${ }^{4}$ Em 1944, o jurista Raphael Lemkin acrescentou um novo termo aos dicionários: genocídio, o assassinato de um povo inteiro. Considerado o mais grave entre todos os crimes, ocorreu repetidamente no século XX.
} 
devir afetado por uma sequência de massacres genocidas da Alemanha a Ruanda, da Armênia ao Camboja, além dos horrores da limpeza étnica praticada na Bósnia ${ }^{5}$. Pessoas morrem de fome no Haiti, no Iraque, no Afeganistão e em outras partes do globo.

Assim, a expressão "direitos humanos", que historicamente representa um grito de liberdade, igualdade e fraternidade de toda a humanidade, revela-se paradoxal e, em verdade, o cume de um idealismo considerado por muitos como ingênuo ou de cínica hipocrisia, quando se confrontam opressores, vítimas das guerras e os meros espectadores que se deparam com uma situação em que a era dos direitos convive com a "era dos extremos", expressão cunhada por Hobsbawm (1994, p. 45) ou, como afirma Barretto (2013, p. 32):

[...] de um lado, proclamam-se em diversos textos legais um número crescente de direitos civis, políticos, sociais, econômicos e culturais, que constituem, na história do direito, a afirmação mais acabada da crença do homem na sua própria dignidade; de outro lado, esses mesmos direitos transformam-se em ideais utópicos, na medida em que são sistematicamente desrespeitados por grupos sociais e governos.

Mutua (2008, p.10) considera que o movimento dos direitos humanos está marcado por uma metáfora muito própria e que guarda relação com um subtexto paralelo e vinculado à grande narrativa histórica dos direitos humanos, que retrata uma relação entre violadores, vítimas e salvadores. Essa construção colonialista (violadores vítimas - salvadores) é considerada uma metáfora tridimensional em que cada dimensão revela uma metáfora em si. Para o autor, essa representação tridimensional do corpus dos direitos humanos e de seu discurso revelar-se-ia unidirecional e previsível; uma construção dicotômica que necessariamente coloca o que é considerado como "bem" contra aquilo que é tido como "mal".

Nesse sentido, por trás dos discursos de justiça, direitos humanos, democracia, desenvolvimento, e mesmo de multiculturalismo, na retórica moderna, subjaz a lógica colonial de uma epistemologia eurocêntrica; a saber, de um padrão de conhecimento que é imposto como universal e categorizante da humanidade. Lógica essa que se ampara na ideia de que alguns (os salvadores) estão em um lugar universal, de tal modo que são a representação do considerado conhecimento universal (adequado, imparcial, equitativo, bom para todos). Por outro lado, os "outros" (violadores-vítimas) são aqueles que se encontram em um lugar particular e localizado e, por isso, devem receber esse conhecimento. Assim, é possível encontrar-se paridades no controle epistêmico que permitiu o desenvolvimento de conceitos como povos inferiores, bárbaros, primitivos e subdesenvolvidos.

Essa visão colonialista e eurocêntrica defende a ideia de que à Europa - e mais contemporaneamente ao Ocidente - impende a missão histórica civilizadora (os salvadores), a fim de retirar o resto da humanidade de seu primitivismo (violadores-vítimas), de sua irracionalidade e de seu subdesenvolvimento, para, então, conduzir tais povos rumo ao progresso e à racionalidade.

\footnotetext{
${ }^{5}$ Antes de ser uma exclusividade nazista, a intenção de eliminar pessoas e povos diferentes, pelo contrário, revelou-se uma das vol.09, nº. 04, Rio de Janeiro, 2016. pp. 1787-1805 1794
} 
A primeira dimensão desse prisma compreende o selvagem e evoca imagens de barbárie. Os atos praticados pelos violadores dos direitos humanos são apresentados como cruéis e inimagináveis, de sorte que são representados como a negação da humanidade.

No modo de ver de Mutua (2008, p. 10) a história dos direitos humanos apresenta o estado como o clássico violador, um selvagem empenhado permanentemente em consumir humanos. Embora a violação, no discurso dos direitos humanos envolva muito mais que tão somente o estado, este é retratado como um instrumento operacional das violações dos direitos.

Os estados se tornam violadores (selvagens) quando sufocam e oprimem a sociedade civil. O "bom" estado controla suas tendências opressivas, purificando-se e internalizando os direitos humanos. O "mau" estado, por seu turno, se expressa por meio de uma cultura antiliberal, antidemocrática ou autoritária. A redenção do estado depende tão-somente de sua submissão às normas dos direitos humanos. O estado é o garantidor dos direitos humanos; ele é também o alvo e a raison d'être das normas de direitos humanos.

Mas a realidade é muito mais complexa. Ainda que a metáfora possa sugerir, não é o estado por si que se constitui como violador ou bárbaro, mas o seu fundamento cultural. De acordo com Mutua (2008, p. 11), o estado somente se torna um violador de direitos quando a " má" cultura supera ou não permite o desenvolvimento da "boa" cultura. Assim, o violador "real" não é o estado em si, mas uma cultura desviada dos direitos humanos.

A selvageria intrínseca, tanto teórica quanto praticamente, ao estado unipartidário, à junta militar, ao estado controlado e fechado, à teocracia, ou mesmo aquela revelada em práticas culturais como a mutilação genital feminina não o são ao estado em si. O estado enquanto tal é neutro, instrumentalizável - um receptáculo - que viola direitos na medida em que implementa o projeto de uma cultura de violações.

A segunda dimensão do prisma apresenta o perfil da vítima, tal como a essência e a ideia de vitimação. A vítima é um ser humano cuja dignidade e valor foram transgredidos pelo violador. A figura da vítima é de um impotente, desamparado, inocente, cujos atributos naturais foram negados pelas ações primitivas e ofensivas do estado ou pela fundação cultural do estado. Razão pela qual a estrutura dos direitos humanos é, ao mesmo tempo, anticatastrófica e reconstrutiva. Anticatastrófica porque está designada para prevenir mais calamidades através da criação de mais vítimas. Reconstrutiva, porque procura reestruturar o estado e a sociedade para reduzir o número de vítimas, ao identificá-las e prevenir as condições que lhes dão origem. Os documentos clássicos dos direitos humanos refletem essas duas estratégias que mutuamente se reforçam.

Importante sublinhar que a concepção de modernidade foi elaborada, num primeiro momento, tendo em conta o contraste com a noção de "primitivo", representada não só pelo passado, mas também pelos outros recém-descobertos, levando à necessidade de superação, consumada pela ilustração. Nessa passagem de uma 
condição inferior para uma condição superior, encontram-se, o jaez para o estabelecimento da hegemonia epistêmica europeia. Nesse âmbito é certo que a produção dos saberes implica a existência de sujeitos capazes de enunciá-los, ou seja, dotados desse poder, e outros que a eles são submetidos, ou seja, que se limitam à posição de meros espectadores quando não relegados à condição de objetos do conhecimento do outro. Nessa conjuntura, alguns possuem credibilidade epistêmica (salvadores) e outros não possuem legitimação para reflexões teóricas consideradas como válidas (violador-vítima).

A terceira dimensão do prisma, segundo Mutua (2008, p. 11), é representada pelo salvador ou redentor, o " anjo bom" que protege, vindica, civiliza, retém e salvaguarda. O salvador é o baluarte da vítima contra a tirania. A simples, ainda que complexa, promessa do salvador é a liberdade: liberdade das tiranias estatais, tradição e cultura. Mas também é a liberdade para criar uma sociedade melhor, baseada em valores particulares. Na história dos direitos humanos, o salvador é o corpus dos direitos humanos em si, tendo a $\mathrm{ONU}$, os governos ocidentais, as ONG's e instituições de caridade ocidentais, como os salvadores reais, redentores de um mundo ignorante e cruel. Mutua (2008, p. 12) considera que essas instituições, em verdade, são meras frentes, na medida em que o salvador é, em última análise, todo o conjunto de normas e práticas de base cultural, inegavelmente inerentes ao pensamento e à filosofia liberal, num Estado de Direito. Esse corpus dos direitos humanos, para o autor, é fundamentalmente eurocêntrico e disso decorre uma série de falhas básicas e interdependentes que são percebidas na metáfora violadores-vítimas-salvadores. Os sistemas jurídicos e suas bases filosóficas mostram-se diretamente influenciados por esse quadro.

Exatamente por conta desse contexto cultural e histórico, a bandeira da universalidade dos direitos humanos resta questionada. Isso porque o entendimento histórico da luta por dignidade humana deveria considerar os esforços das sociedades subjugadas pela tirania e pelo imperialismo europeu. Desafortunadamente, tais esforços não fazem parte da narrativa oficial dos direitos humanos. Alguns dos mais importantes eventos que precederam o pós-1945 relacionados ao movimento dos direitos humanos, incluem tanto as campanhas abolicionistas promovidas nos EUA quanto as lutas anticoloniais na África, Ásia e América Latina e as lutas pelo sufrágio feminino e por igualdade de direitos.

A metáfora violador-vítima-salvador e sua narrativa recusam a influência cruzada das culturas e, ao invés, promovem o ideal eurocêntrico colonialista. A metáfora tem como premissa a transformação pelas culturas ocidentais das não-ocidentais num protótipo eurocêntrico e não a confecção de um mosaico multicultural. Disso resulta um processo que Mutua (2008, p.12) denomina "othering", ou seja, a criação de clones inferiores, de fato cópias silenciosas do original. Como exemplo, o autor cita a democracia política do ocidente que está em vigor e se revela como um elemento orgânico dos direitos humanos. Culturas e povos "selvagens" são vistos como estando fora da órbita e das implicações dos direitos humanos, fora do regime da democracia política. Essa é a distância dos direitos humanos que permite a certas culturas criar vítimas. A democracia política é então vista vol.09, no. 04, Rio de Janeiro, 2016. pp. 1787-1805 1796 
como uma panaceia.

\section{O PROJETO ILUMINISTA EM CRISE E OS DIREITOS HUMANOS}

Os direitos humanos que a modernidade consagrou sofrem as consequências do que Rouanet define como "mal-estar moderno, ou num mal-estar na modernidade", ao se referir ao sentimento de repulsa contra o modelo civilizatório que deu contornos a própria modernidade: o iluminismo. Segundo as palavras do autor: "O Iluminismo institucionalizado é vivido como repressivo. O que não deixa de ser paradoxal. Afinal, o objetivo do projeto iluminista era emancipatório" (ROUANET, 1987, p. 37).

Como pode um projeto que se forjou na supervalorização do homem, em oposição a uma visão de mundo teocêntrica, visando a sua emancipação se voltar para o seu oposto? A opção por um modelo liberal de organização das relações sociais, fundado numa lógica de mercado, em que a dinâmica é cadenciada pela competição e referendado pelo discurso de legitimação das ciências, levou à exacerbação do racionalismo e, por via de consequência, a uma outra visão iluminista, agora, voltada para a manutenção do domínio e do poder.

O racionalismo da modernidade é o da razão instrumental, técnica, uma espécie de razão que dilacera a existência humana em sua plenitude, reduzindo-a a um de seus aspectos, e, " revela potência, dominação, desmistificação, e age ao modo de algo que rompe o véu da ignorância, que desvirgina o mundo, o mistério, a natureza e, exatamente por isso, se converte em razão instrumental." (BITTAR, 2015, p. 03).

Talvez aqui resida parte da resposta ao questionamento de Barretto (2013, p. 25) quando formula esta indagação "Como podemos explicar que nem todos os humanos têm humanidade no mundo dos direitos humanos?". Mais que isso, uma imensa massa de indivíduos que representa a maioria da população mundial não possui a titularidade dos direitos humanos, muito embora seja objeto de discursos de direitos humanos. Desse modo, além da compreensão do que venham a ser direitos humanos e o discurso que os contempla no marco da modernidade que os gerou, necessário se faz entender e refletir sobre os motivos que levam a sua ineficácia e as perspectivas que apontem para superar tal situação.

Como explicar o paradoxo do discurso do corpus dos direitos humanos que ao mesmo tempo são usados como arma contra a anarquia, para a instauração do absolutismo ou um remédio adotado pelo liberalismo para pôr fim ao absolutismo, mas que ao mesmo tempo serviram aos regimes totalitários para expor as mazelas do liberalismo e que, em última instância poderiam levar ao retorno da anarquia, como bem adverte Villey (2007, p. 37).

Douzinas, ao referir-se a essa questão, considera que há que se ter em foco a finalidade (o fim) original dos direitos humanos, que é a resistência. De sorte que, quando eles perdem essa razão de ser, por exemplo, quando se tornam a mais recente versão da missão "civilizadora" em Kossovo, no Iraque e no Afeganistão, sua 
função e seu uso chegam ao fim. Os ideais perdem seu valor quando chamam a polícia e a força aérea para promovê-los. Um anjo protegido pela polícia perde sua virtude. (...) O triunfo dos direitos humanos está afogado na catástrofe" (DOUZINAS, 2015, p.01).

Diante do saldo negativo apresentado pela realidade paradoxal em torno do discurso dos direitos humanos nos últimos tempos, Sousa (2013, p. 13) questiona: "será a hegemonia de que goza hoje o discurso dos direitos humanos o resultado de uma vitória histórica ou, pelo contrário, de uma derrota histórica?". Para o autor, qualquer que venha a ser a resposta, os direitos humanos como "linguagem hegemônica da dignidade humana" foram estabelecidos como instrumentos do mesmo modo que outros tantos, numa conjuntura que legitima e perpetua a opressão. Então, em que medida poderiam os direitos humanos ser utilizados para modificar esse status quo e, se possível, como seria isso exequível? Além disso, se a linguagem dos direitos humanos permite a exclusão, a discriminação e a opressão, haveria outras linguagens dos direitos humanos? E, caso haja, estariam aptas a contribuir para promover a superação das violações e injustiças contra os direitos humanos?

A modernidade erigiu um edifício ético fundado na separação entre o dever e da felicidade, em lugar da separação entre virtude e felicidade, onde a moral é definida como o dever categórico despojado de qualquer benefício para o sujeito compassivo. A obrigação pura é a tônica dessa sociedade que substitui o fundamento teológico pelo laico; nela o caráter absoluto do imperativo religioso abre espaço para a prevalência dos deveres individuais e coletivos. Seu projeto envolveu uma justificação racional apartada da moralidade, cuja preocupação central está focalizada em encontrar uma justificação racional, independente da tutela teológica e das tradições, no intento de conferir à moral total autonomia consubstanciada em princípios universais. Mas, segundo MacIntyre (1988, p. 52), " todo projeto que tivesse esta forma estava fadado ao fracasso por causa de uma discrepância ineliminável entre, de um lado, sua concepção comum de regras e preceitos morais e, de outro lado, o que era comum - a despeito de grandes divergências - às suas concepções da natureza humana”.

A concepção jurídica da Modernidade balizou a expressão dos direitos humanos, percebidos como universais. Esse processo ganha visibilidade histórica na exata medida em que a centralização do exercício do poder político e a constituição dos Estados nacionais se estabelecem como alicerces para o processo de crescimento exponencial do sistema capitalista liberal. O direito objetivo manifesta-se, desse modo, como expressão do conhecimento moderno, tido como científico.

A concepção individualista liberal de ser humano e de sociedade, de viés burguês, consolidada e tendo como referencial a Revolução Francesa ${ }^{6}$, recebe a sustentação normativa do direito moderno. A modernidade concebe o direito a partir do estabelecimento de um patamar de igualdade formal entre todos os cidadãos, numa perspectiva de cidadania que se mostra adequada à feição ideológica burguesa. O próximo e necessário passo 
dessa noção de direito moderno se dá na afirmação da autonomia humana e da racionalidade ligada à perspectiva lockeana material do desenvolvimento da propriedade, tida como condição de liberdade e de trabalho.

Cumpre observar que, como bem elucida Mutua (2008, p. 16), em sua origem, a criação da concepção de direitos humanos não se destinava a salvação ou civilização dos não-europeus, muito embora esses impulsos humanistas tenham servido como impulso aos esforços anti-escravagistas abolicionistas do século XIX. De toda sorte, há que se reconhecer que nem a escravidão dos africanos, nem a clássica colonização de asiáticos, africanos e latino-americanos pelos europeus, com suas terríveis atrocidades, foram suficientes para mover o Ocidente a criar o movimento dos direitos humanos.

A concepção de direitos humanos nasce a partir de uma dimensão simbólica do sistema capitalista, tendo em vista que a dignidade humana só poderia ser concebida a partir dos padrões europeus de homem e de dignidade, fundamentos em si da própria modernidade, racional, lógica e positivista, num universo dominado pelo Estado de Direito, cujo paradigma era o Direito Civil.

Mutua (2008, p. 15) considera que, muito embora o movimento dos direitos humanos esteja localizado dentro do continuum histórico do eurocentrismo racional em sua missão civilizatória, ou seja, objetivamente como um ataque às culturas não-europeias, é sintomático notar que foram as atrocidades europeias e não as não europeias que os suscitaram.

Foi necessária a exterminação genocida dos judeus na Europa - um povo branco - para iniciar o processo de codificação e universalização das normas de direitos humanos. Assim, muito embora o Tribunal de Nuremberg tenha sido questionado por alguns, seja por seu caráter de tribunal de exceção ${ }^{7}$, seja por seu viés nitidamente político, é a sua promessa que é significativa. Pela primeira vez, os poderes maiores estabeleceram uma linha demarcatória de conduta não permitida aos estados em relação a seu próprio povo e criaram o conceito de responsabilidade coletiva pelos direitos humanos. Mas não se pode olvidar a ironia contida no fato de que tenham sido as potências coloniais brutais que tenham defendido o Julgamento de Nuremberg e a adoção da Carta Universal dos Direitos Humanos ${ }^{8}$.

Muito embora tenham sido edificadas as figuras do salvador como europeu, do violador (selvagem) ou da vítima como não-europeus, não se pode negar que Adolf Hitler foi a quinta-essência da selvageria. A prova inconteste dessa afirmação chegaria com a abertura dos portões dos campos de concentração da Alemanha

\footnotetext{
${ }^{6} \mathrm{O}$ fato é que a narrativa dos direitos humanos salientou somente as revoluções burguesas (em especial a francesa e a estadunidense).

${ }^{7}$ No tocante à crítica de que Nuremberg foi um tribunal de exceção não há como negar. Os juízes foram escolhidos pelos vencedores sem qualquer critério prévio. O tribunal foi extinto após ter proferido o julgamento. As sentenças eram 'negociadas' entre os juízes. (MELLO, 1997, p. 441).

${ }^{8}$ Importante considerar que duas das mais antigas e prestigiadas organizações não governamentais de direitos humanos - a Comissão Internacional de Juristas (CIJ) e a Anistia Internacional (AI) - foram criadas para lidar com as violações dos direitos humanos na Europa, não no Terceiro Mundo. (MUTUA, 2002, p.14).
} 
nazista e a reação dos fiéis servidores de Hitler quando instados a se pronunciarem sobre seus atos. As abominações e o legado mortal de seu regime promoveram a eclosão do movimento dos direitos humanos.

Assim, a mesma modernidade e suas Luzes que pretenderam libertar o homem, elevando a liberdade ao extremo, levaram também a uma fragmentação e negação da realidade e do próprio homem que diante de tantas possibilidades se sente perdido. A pretensa liberdade não emancipa, aliena; quando não exclui, sectariza.

Sloterdijk (2011, p.p. 33-38) aponta a impossibilidade de uma relação sã do iluminismo de hoje com a sua própria história, na medida em que "o Iluminismo recalca conscientemente o rude realismo das doutrinas mais antigas da sabedoria, paras as quais era evidente que a massa não possui o senso comum e a razão é o apanágio de alguns. $\mathrm{O}$ elitismo moderno vê-se obrigado a esconder-se sob um código democrático".

O autor reconhece que nos séculos XVIII e XIX o Iluminismo, a despeito de todas as "crueldades e de todos os reveses da evolução", sob o signo do progresso possibilitou grandes conquistas, e enumera como exemplos “a imprensa, o caminho-de-ferro, a assistência social, a penicilina - quem poderá pôr em dúvida que se trata de inovações notáveis no 'jardim humano'? "(SLOTERDIJK, 2011, p. 39).

Sloterdijk (2011, p. 39), ao se referir ao mal-estar pelo qual o mundo moderno é marcado, vai mais além e aponta para as mazelas decorrentes do próprio Iluminismo, não como uma desvirtuação, mas como a ele inerentes, o qual não pode existir sem a "destruição do pensamento confinado num ponto de vista e a dissolução das morais perspectivo-convencionais; psicologicamente, que é acompanhado por uma dispersão do eu; e, literária e filosoficamente, pelo declínio da crítica". E avança por demarcar que "desde as atrocidades técnicas do século XX, de Verdun ao gulag, de Auschwitz a Hiroshima, a experiência escarnece de todos os optimismos." (SLOTERDIJK, 2011, p. 39).

O projeto iluminista que originalmente acenou com a possibilidade de a humanidade construir o seu próprio destino, através da utilização da ciência como um saber a serviço da humanidade, que suscitou a superação das necessidades com o desenvolvimento das forças produtivas, que libertou a moral no sentido da liberdade concreta e que concebeu uma ordem em que o cidadão pudesse ter seus direitos tutelados e garantidos pelo Estado, agora não mais opressor, que estabeleceu uma doutrina de direitos humanos universal, pautada pela abstratividade, tendente a transcender seus próprios limites tanto espaciais quanto temporais, apta a novas apropriações e novos objetivos políticos, parece ter gestado o seu oposto.

O projeto iluminista parece fracassado. Os motivos para esse fracasso, entre tantos possíveis, talvez residam na opção promovida pelo Ocidente por um modelo liberal de organização das relações sociais, fundado numa lógica competitiva desvinculada dos fins humanos e por um discurso de legitimação das ciências pelo desempenho e pela eficácia, por uma ordem jurídica procedente de um Estado fechado em suas leis, mas que paulatinamente " desde Hobbes até Kelsen, desmanchou-se no ar, parodiando a célebre frase marxista, quando a realidade social mutante invadiu o espaço jurídico positivado e colocou em questão as suas principais categorias" vol.09, no. 04, Rio de Janeiro, 2016. pp. 1787-1805 
(BARRETTO, 2013, p. 18); nessa conjuntura os direitos humanos se revelam como "individualistas, seculares, culturalmente ocidente-cêntricos e Estado-cêntricos, quer quando visam controlar o Estado, quer quando pretendem tirar proveito dele, (...) fragilizados enquanto gramática da dignidade humana."(SANTOS, 2013, p. 109).

Ao refletir sobre os diversos fatores que contribuem para que se considere a crise dos direitos humanos Douzinas (2015, p. 02), aponta que um deles é a apreensão de seu discurso tanto pelo poder público quanto pelo privado. Na medida em que governos, instituições internacionais, juristas e diplomatas se apoderam dos direitos humanos, estes têm todo seu poder contido e sua finalidade destruída. O autor não nega que a institucionalização dos direitos humanos seja útil, mas atenta para o fato de que a sua reprodução em códigos, tratados e convenções é uma forma de os governos, seus maiores violadores, serenarem sua consciência coletiva de maneira pública, aproximando-se do ponto de vista de Mutua (2008) quando este se reporta à já analisada patologia da autorredenção.

\section{CONSIDERAÇÕES FINAIS}

Na medida em que o conjunto dos direitos humanos repercute profundamente em todas as sociedades humanas, em particular nas não ocidentais, necessário se faz a promoção de uma ampla discussão sobre a agenda política do movimento dos direitos humanos e todas as contradições inerentes.

Reconhecer as determinações históricas de um objeto é tratá-lo com base na dinâmica que o conduz na trajetória da história e que ao, mesmo tempo, permite um esboço singular em cada época. É reconhecer as implicações que as modificações de cada fase da história imprimem no modo de perceber e de fazer a própria história. É negar a naturalidade dos fatos, é dotá-los de intencionalidade.

Assim sendo, as categorias da totalidade, do movimento, da contradição, da análise que definem a dialética enquanto caminho investigativo, parecem imprescindíveis para uma investigação que se proponha diagnosticar objetos cuja problemática se ancore nas contradições de um modelo de direitos humanos fundado na lógica eurocêntrica, conforme aquela aqui apontada.

Os fundamentos teóricos do discurso dominante dos direitos humanos tem sido objeto de vasta investigação, o que, num primeiro momento, poderia levar à suposição pela qual as reflexões em relação a esse tema já estariam plenamente esgotadas e que, por conseguinte, não seriam merecedoras de outras contribuições.

No entanto, e muito ao contrário, o que se pode perceber é que os direitos humanos são considerados, tal como observado ao longo do presente ensaio, seja como um desdobramento consequente do pensamento liberal, seja como produto das lutas políticas europeias a partir da modernidade, tendo em seu cerne o lastreio nuclear do liberalismo clássico e suas ideias de liberdade individual e igualdade formal. Por mais que a principal 
característica dessa tradição seja a valorização dos indivíduos, juridicamente considerados, por meio da concessão de direitos decorrentes da autonomia e do exercício do livre-arbítrio, decorrentes de sua racionalidade, o que se percebe na realidade da práxis objetiva das sociedades contemporâneas, caminha em sentido diverso.

De todo modo, os defensores desta concepção antropológico-filosófica sustentada na ideia de racionalidade, consideram que os direitos humanos se constituem como um projeto moral, jurídico e político, produto da modernidade do Ocidente, cuja experiência, maturidade e autoridade o credenciaram a exportar ou transplantar para o resto do mundo. Razão pela qual, as origens dos direitos humanos têm pouco ou nada a ver com a história e a racionalidade dos povos não ocidentais.

Diante desse quadro em que, objetivamente, a feição sobre a qual foram desenhados os direitos humanos reflete um cenário europeu, fundado num liberalismo individualista e opressor que impacta sobremaneira o discurso dos direitos humanos, urge buscar-se novas formas de tradução que possam se configurar possibilitadores da superação da ineficácia e da incompletude.

Isso significa, mais que tudo, refletir criticamente sobre nossa contemporaneidade, as perspectivas que se descortinam e como o Direito, enquanto reflexo e motor da sociedade, pode desempenhar um papel de fundamental importância na ruptura com os modos de vida dominados pela racionalidade asséptica, pelo individualismo egoísta, pela lógica reificada do mercado, bem como na afirmação de uma ética em que o Outro não figure como mero opositor ou concorrente.

Cumpre ao Direito o arranjo entre legalidade e eticidade para que os ideais democráticos e a vida em todas as suas múltiplas manifestações se realizem na garantia da justa afirmação de um Humanismo includente e possibilitador da realização coletiva.

A promoção de um olhar crítico-analítico permite vislumbrar as fraquezas da teoria tradicional de direitos humanos e incita a avançar, mas, importante que se aponte, sem os arroubos das rupturas totalitárias, sem desconsiderar ou abandonar as conquistas normativas já alcançadas e consolidadas, reconhecendo que há um saldo de conquistas que lograram atingir pontos relevantes no caminho do reconhecimento de direitos e garantias e não cabe retornar a um ponto zero.

Ao contrário, repensar os direitos humanos significa a promoção de um outro olhar distante do eurocentrismo que considere o ideário dos direitos humanos como produto de um desenvolvimento inclusivo e global, mas que tenha em conta, tanto a existência como a participação dos mais diversos atores sociais habilitados e uma sociedade humana, cujo signo, para além dos egoísmos mesquinhos, nesse processo de construção, seja o da alteridade, solidariedade e da tolerância.

Uma tal elaboração exige a abrangência inclusiva, necessariamente, de uma multiplicidade de atores cujo contributo tanto no nível cultural quanto social, há de ser de fundamental importância para a mudança da concepção, dos rumos, os objetivos e efetividade dos direitos humanos. 


\title{
THE FRAGILITY OF THE NOTION OF HUMAN RIGHTS IN THE FRAMEWORK OF THE CRISIS OF THE FOUNDATIONS OF MODERN REASON
}

\begin{abstract}
The question addressed in this paper concerns a critical reflection about the reasons for a lack of effectiveness of human rights, discussing it from the thought called by Santos as counter-hegemonic. The interest for reflection on the fundamentadora failure of the logic of human rights in its Eurocentric character arises in that, although the theoretical foundations of human rights already have made in widely researched subject, which does not mean that it does not deserve other looks, in turn issues the ineffectiveness when the normative application of human rights are causing further deepening. The proposal is from a retrospective of jusfilosófico and political context in which was born the notion of "human rights", pointing out its foundations, and inherent in its historical effectiveness issues, taking into account the contribution of the natural law and legal positivism, rational modernity, logical and positivist in a universe dominated by the rule of law. It also proposes to place the speech of human rights in the current socio-political context of crisis of the reason fundamentals, foundational paradigm and structuring of society in need of a change. It is taken as theoretical thinking of authors like Michel Villey, Douzinas Back, Gilles Lipovetsky, Peter Sloterdijk, Makau, Mutua and Boaventura de Souza Santos, among others. In this direction, in front of the goal set forth herein and presented in the course of the text, it is believed that the guidelines derived from the dialectical method seem appropriate to the orientation of the presented research development. Privileging the dialectical method implies recognizing that the study aims to make a critical reading of the notion of human rights. It is intended to point out evidence to demonstrate human rights as a legal production and Eurocentric feature policy, within a strictly rationalist bias and opinionated, own of modernity, in order to highlight the hypothesis that the fragility of the notion of rights humans and their inadequate reasoning, are associated with the weakness of its normative nature and an exaggerated rationalism that, contradictorily, the legal surpasses the human, ethical and solidarity.
\end{abstract}

Keywords: Human Rights; Eurocentrism; modernity; inadequate reasoning

\section{REFERENCIAS}

BARRETTO, Vicente de Paulo, O fetiche dos Direitos Humanos e outros temas, 2a. Ed., Porto Alegre: Livraria do Advogado, 2013.

BARROSO, Luís Roberto. Fundamentos Teóricos e Filosóficos do Novo Direito Constitucional Brasileiro.
Revista da EMERJ, v. 4, n. 15, 2001. Disponível em: http://www.emerj.tjrj.jus.br/revistaemerj_online/edicoes/revista15/revista15_11.pdf. Acesso em 30 jul 2015.

BITTAR, Eduardo. Razão e afeto, justiça e direitos humanos: dois paralelos cruzados para a mudança paradigmática. Reflexões frankfurtianas e a revolução pelo afeto. Disponível em: http://www.dhnet.org.br/direitos/militantes/eduardobittar/bittar_razao_afeto_justica_dh.pdf. Acesso em 23 jul 2015.

CHUWA, Leonard Tumaini. African indigenous ethics in global bioethics: interpreting Ubuntu. New York: Springer, 2014.

DOUZINAS, Costas. Os ideais perdem seu valor quando chamam a polícia e a força aérea para promovê-los. 
http://www.ihuonline.unisinos.br/index.php?option=com_content\&view=article\&id=2563\&secao=293.

Acesso em: 31 ago 2015.

DUSSEL, Enrique. Europa, modernidade e eurocentrismo. In: LANDER, Edgardo (Org). A colonialidade do saber: eurocentrismo e ciências sociais. Perspectivas latino-americanas. Buenos Aires: Colección Sur Sur, CLACSO, setembro 2005.

FROMM, Eric. A arte de amar. São Paulo: Martins Fontes, 2006.

GIACOIA JUNIOR, Oswaldo. Filosofia da cultura e escrita da história: Notas sobre as relações entre os projetos de uma genealogia da cultura em Foucault e Nietzsche. Estudos Nietzsche, Curitiba, v. 5, n. 1, p. 3-34, jan./jun. 2014.

HOBSBAWM, Eric. The age of extremes: a history of the world, 1914-1991. New York: Pantheon Books, 1994.

KANT, Imannuel [1783]. Resposta à pergunta: o que é o esclarecimento? Tradução de Luiz Paulo Rouanet. Disponível em: http://ensinarfilosofia.com.br/_pdfs/e_livors/47.pdf. Acesso em 10.01.2015.

LAFER, Celso. A internacionalização dos direitos humanos: Constituição, racismo e relações internacionais. São Paulo: Manole, 2005.

Resistência e realizabilidade da tutela dos direitos humanos no plano internacional no limiar do século XXI. In: AMARAL JR, Alberto do; PERRONE-MOISÉS, Claudia (Org.). O cinqüentenário da Declaração Universal dos Direitos do Homem. São Paulo: Editora da Universidade de São Paulo, 1999.

LIPOVETSKY, Gilles. O crepúsculo do dever. A ética indolor dos novos tempos democráticos. Alfagride: Dom Quixote, 2010.

MACDOWELL SANTOS, Cecília. Os direitos humanos são resultado das relações de poder. Disponível em: http:/ /www.huonline.unisinos.br/index.php?option=com_content\&view=article\&id=3629\&secao=349, acesso em 06 jul 2015.

MACINTYRE, Alasdair. After virtue, 2a. ed., Londres: Duckworth, 1985.

Depois da Virtude. Tradução de Jussara Simões, Revisão Técnica de Helder Buenos Aires de Carvalho. São Paulo: EDUSC, 2001.

Whose justice? Which rationality? Londres: Duckworth, 1988.

MELLO, Celso Duvidier de Albuquerque. Direitos Humanos e Conflitos Armados. Rio de Janeiro: Renovar, 1997.

MUTUA, Makau. Human Rights A Political and Cultural Critique, University of PennsylvaniaPress, 2008.

QUIJANO, Anibal. Colonialidade do poder, eurocentrismo e América Latina. In: A colonialidade do saber: eurocentrismo e ciências sociais. Perspectivas latinoamericanas. Edgardo Lander (org). Colección Sur Sur, CLACSO, Ciudad Autónoma de Buenos Aires, Argentina. Setembro 2005.

SAID, Edward Wadie. Humanismo e crítica democrática. São Paulo: Companhia das Letras, 2007.

SANTOS Boaventura de Sousa. A Gramática do Tempo - Para uma nova cultura política. São Paulo: Cortez vol.09, nº. 04, Rio de Janeiro, 2016.pp. 1787-1805 1804 
Editora, 2006.

Para além do Pensamento Abissal: Das linhas globais a uma ecologia de saberes. Revista Crítica de Ciências Sociais, 78, outubro 2007: p. 3-46.

Se Deus fosse um activista dos Direitos Humanos, Coimbra: Almedina, 2013.

Pela Mão de Alice, o Social e o Político na Pós Modernidade. São Paulo, Cortez, 1995.

SLOTERDIJK, Peter. Crítica da razão cínica, Lisboa: Relógio D’água, 2011.

VILLEY, Michel. O direito e os direitos humanos. SP: Martins Fonte, 2007.

Trabalho enviado em 02 de fevereiro de 2016.

Aceito em 02 de maio de 2016. 